\title{
1. Prologue to the Research Handbook of Global Leadership: Making a Difference
}

\author{
Lena Zander
}

\section{HOW IT ALL STARTED ...}

The Research Handbook of Global Leadership: Making a Difference came into existence as a book project in Limerick, Ireland where serendipitously two happenings occurred on the same sunny day. One was that Ms Francine O'Sullivan, publisher at Edward Elgar Publishing, inquired whether I was interested in editing a research handbook of global leadership. I was. And two, Professor Nakiye Boyacigiller in her keynote speech mentioned how the move from the United States to Turkey had made her reflect and focus on the importance of making a difference. The keynote brought vivid memories of my own father to mind. How he had, when he worked and we lived in Africa, Asia and Europe, spoken to me, as I grew up, about leadership, and about what was the most important: "it is what you do and how you act in everyday life that matters". Like generations of family members before him, he would emphasize how a leader should be a role model. Always. And in so doing trying to make a difference to the people around themselves. These remembrances resulted in this book project on global leadership taking on a personal, additional important role - that of making a difference as a leader.

I invited scholars who are knowledgeable, insightful, reflective and importantly want to make a difference with their research and teaching. The invitation placed particular emphasis on three issues; first, that the choice of topic was entirely open as long as it contributed to our understanding of leadership in the global arena. Second, it should have implications for making a difference regarding global leadership. And third, the chapters could be theoretical or empirical, or take the form of shorter idea-based essays, whichever format the authors preferred for conveying their ideas, research and scholarly insights. The open and rather loosely framed invitation led to that scholars, who have global leadership at the core of their research, engaged in conversations with those whose research touch on the contours of global leadership. Thus, offering both inside and outside perspectives while not shying away from critical viewpoints, the ambition of the volume is to provide an exceptional set of contributions to the field of global leadership. Before outlining the structure of the book and introducing the chapter contributions, a few words on the intellectual journey towards the realization of the Research Handbook of Global Leadership: Making a Difference.

\section{CONTRIBUTORS ENGAGING IN CONVERSATIONS}

Early on during the project, I organized a workshop in Sigtuna, Sweden. Authors were invited to submit their draft chapters to the workshop, where they would be able to present their work, receive feedback from a dedicated discussant and the rest of the group in addition to my comments. In the lovely milieu of Sigtuna Folkhögskola with its view over the small quaint 


\section{Research handbook of global leadership}

historical town of Sigtuna (founded in $970 \mathrm{AD}$ ) by the waterside of Lake Mälaren, a stimulating exchange of ideas about leadership took place. The conversation was perhaps influenced by the atmosphere of Sweden's first town, which had been developed according to a city plan during the Viking era, and quickly became a vibrant cosmopolitan trading center where languages and cultures met and mixed.

To many scholars writing is a lonely endeavor. To others this is the best part, but wherever you find yourself on the scale from the need for society to the need for solitude, you will most probably agree that engaging in research conversations with knowledgeable others is not only beneficial but also enjoyable. We concentrated on global leadership, culture, and the ideas proposed in the chapter drafts, but we also had time to ponder on how this book could be made relevant to a broad(er) readership. One suggestion that came up was that each chapter could, in a designated and systematic way, provide ideas for further research as well as briefly outline the chapter's relevance for educators and practitioners. This was agreed upon, and the result in the form of marked textboxes on these topics are visible at the end of each chapter in this volume.

Another suggestion was to take the idea behind the book and the individual chapters to a wider academic audience, such as that at the Academy of Management's annual conference, which we did. The overall purpose of our proposed panel symposium was to take to heart the queries of how people, teams and firms can make a difference with global leadership, and how universities and business schools can educate global leaders. It turned out that there was such a positive response from the chapter authors that the panel had to be divided into three "sub-panels", all to be held sequentially at the same session. On the day of the panel symposium we were gathered in a large conference room, exceptionally full, where an enthusiastic audience engaged in conversation with members of the three panels, and each other. Needless to say, this impressive turnout posed quite a challenge to the panel participants as well as to us as organizers in terms of timing, managing the flow of input into the discussion and providing a relevant summary at the end of the session. What became overwhelmingly clear was that the questions of making a difference with global leadership from a people, team, firm, university and business school perspective had definitely engaged the participants at the panel symposium, bearing promise of an interest in the collection of chapters in this volume.

\section{A MAP OF THE BOOK}

Across the chapters, global leadership is examined from different perspectives, namely that of leaders and teams, firms and inter-firm partnerships as well as universities and business schools, dividing the volume into three parts. Interestingly, given the open nature of the invitation to participate in this book project, it became clear already from the outset that certain themes were prevalent across the submitted chapters.

Keywords such as cultural multiplicity, cultural competence, awareness and mindset, cultural boundary spanning, blending and bridge making as well as bicultural and multicultural identities are characteristic of the first part of the volume where global leaders and teams are in focus. The second part is characterized by keywords such as responsible leadership, virtuous leadership, inclusive leadership and shared leadership, but also by how firms can develop leaders, or how leaders develop through inter-firm partnerships. The keywords of the third part include developing global competencies, social consciousness and intersectional understand- 


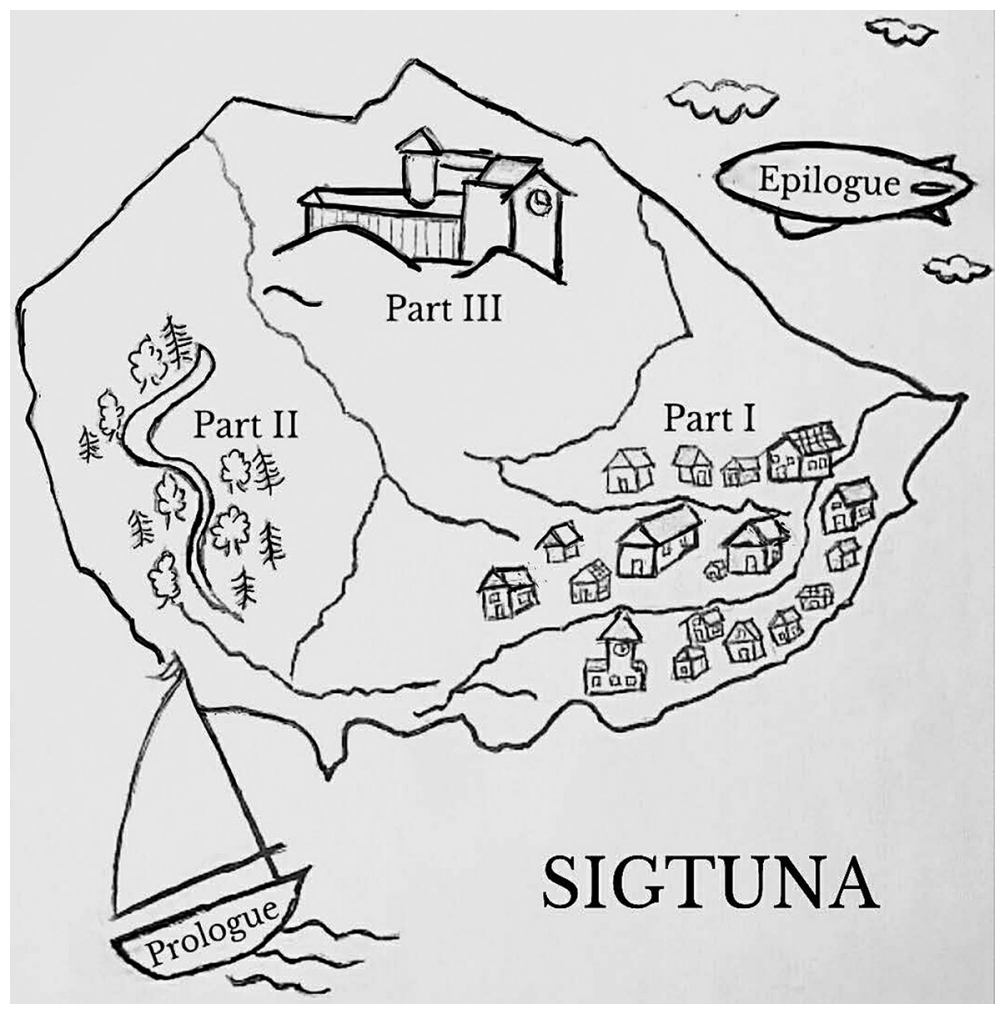

\section{Figure 1.1 Map of the book}

ing among students, but it also contains reflections on how business schools and universities can interact with practitioners and influence education of the future. The last contribution in the volume is an epilogue that takes a look at the chapters in the volume while exploring the idea of developing holistic leaders.

A map modeled on the town of Sigtuna, where we held our initial workshop, is depicted in Figure 1.1. The main streets and buildings, where people meet, talk and work together, represent Part I of this volume with its focus on global leaders and teams. Turning to the tree-covered green areas of Sigtuna on the map, we find Part II on global firms and inter-firm partnerships with its focus on responsibility and sustainability, doing good, growing, and developing as leaders, and standing firm when the cold winds blow. Moving on to Part III with a focus on universities and business schools, it is a short walk uphill on the map to arrive at the place where the Sigtuna workshop was held. As it is a venue for education, it symbolizes innovative approaches to educating global leaders for the future, as well as universities and business schools taking on new roles and partnering with practitioners.

Hovering above Sigtuna is an aircraft named "Epilogue", providing a helicopter view of the book chapters, but also taking a critical look at developing holistic global leaders for the future. And then there is the sailing boat called "Prologue". A boat that has experienced (much) more than expected, from smooth sailing in running wind when making progress, to stormy waves of unpredictability, followed by non-motion when there is no wind in the sails at 
all. Sometimes tedious zig-zagging tacking up against the wind would work. At other times the sailing boat would end up stuck in irons with the sails flapping uselessly. But eventually the ship reached the shore carrying its prologue to the Handbook of Global Leadership: Making a Difference.

\section{AND THEN THERE WERE THREE PARTS ...}

As an appetizer, or perhaps a trailer, the intent of the following brief introductions to the chapters is to inspire further reading, but also to give an overview of the range of contributions in each part of this volume.

\section{Part I - Leaders and Teams: Making a Difference with Global Leadership}

Chapter 2 places leadership firmly in its global cultural context. Gundula Lücke examines the cultural implications for leaders (and teams) in "Multicultural leadership: Keeping multiplicity alive and well". Leadership is, in her view, "by definition cultural as perceptions, understandings and actions are guided and shaped by the culture(s) they are embedded in". Cultural multiplicity thus becomes a fundamental resource to global leaders, which they need to recognize, engage, leverage and mobilize in their leadership. Lücke proposes that integrative and generative leadership, and the interaction of the two, are critical processes underlying multicultural team activity.

Integrative leadership involves sharing and unifying the processes necessary to handle multicultural challenges, communication and coordination, while generative leadership draws on cultural meanings to find new solutions, engages in the exploration and exploitation of novel opportunities and adapts flexibly to changing environments. Global leaders practicing integrative and generative leadership, based on underlying sociocultural dynamics, will be at the helm of making a difference with global leadership.

In Chapter 3 on "Global leadership: Sustaining classic managerialism", Stefan Sveningsson and Mats Alvesson provide us with a critical treatment of the concept of global leadership. In their detailed scrutiny, they problematize and demystify global leadership, its underlying assumptions, and how in their view it is deceptively framed as an all-embracing and intuitively good discourse. Moving away from a leader-centric conceptualization, Sveningsson and Alvesson instead propose that leadership is a socially constructive influencing process. Exercising leadership, the authors argue, fundamentally means influencing (and changing) how people think about what is desirable, possible and necessary to accomplish. It may not always be what the leader does, but instead how it is interpreted by others that is important. Leadership connects to culture, and to make a real difference attention is needed on how people make sense of work, relations, interactions, processes and organizational objectives.

Chapter 4 by Lena Zander, Audra Mockaitis, Anne-Wil Harzing together with 20 country co-investigators is entitled "Action intent: Getting closer to leadership behavior in 22 countries". When faced with the same situation/task or circumstances (as described in leadership scenarios) and when given a set of identical alternatives, leaders in 22 countries are shown to respond or react differently to most of the leadership situations. Notably, even when their action intent is similar, the percentage of respondents selecting the same action alternatives as first-ranked choices varies greatly across countries, and can be meaningfully explained using 
culturally endorsed leadership theory. Notably, in some countries, for some situations, there is within-country variation in preferred action alternatives. Zander and colleagues propose that in order to make a difference, a global leader not only needs to possess cultural knowledge and awareness. An understanding is also required for whether there are taken-for-granted leadership actions to consider, and whether or not there are large degrees of freedom in how to approach a leadership situation.

Chapter 5 entitled "The motivational forces and moral imperatives of relational models: Implications for global leadership" is authored by Markus Vodosek and Lena Zander. Social relationships wield strong motivational forces, but expectations vary greatly across cultures. People organize their social relationships according to four basic models: Communal Sharing, Authority Ranking, Equality Matching and Market Pricing. Vodosek and Zander address what happens when a leader engages in a culturally incongruent activity, which clashes with subordinate or team member social relationship expectations. They suggest that congruence is motivating, and incongruence demotivating, when the moral imperative associated with a relational model is important to the subordinate (or team member). However, if the moral imperative is unimportant to them, congruence will lead to functional behavior, while incongruence will lead to dysfunctional behavior on their part (e.g., shirking work). Global leaders who wish to make a difference need to understand the motivational forces and the possible consequences of non-congruent perceptions of social relationships.

Chapter 6 by Kristiina Mäkelä, Jakob Lauring, Christina Butler, Hyun-Jung Lee, Gundula Lücke, Christof Miska, Cecilia Pahlberg and Günter Stahl is entitled "Meeting the challenges of globalization in order to make a difference: Implications for teams and team leadership". Globalization brings on three challenges of particular concern to global team leaders: stakeholder diversity (the increase in number of internal and external stakeholders to manage), multiple boundaries (the need to interact across more and different types of boundaries) and local-global tensions (an increasing necessity to integrate local responsiveness and global coordination). Mäkelä and colleagues provide an empirical illustration of how the general manager of a Japanese branch of a German bank used strategies and solutions that involved boundary spanning, bridging and blending capabilities to exemplify how team leaders can meet global challenges. The authors emphasize that by leveraging such capabilities, team leaders can make a difference and manage the effects of globalization on the team.

Chapter 7 by Yih-teen Lee and Susan Schneider is entitled "Making a difference: Managing identities and emotions in multicultural teams". The empirical findings from examining multiple identities in multicultural teams of master's students indicate that when social identities, especially based on national identity or country of origin, become salient in teams, negative emotions, less effective communication and conflict are likely to occur. But also the reverse holds, namely that negative emotions, difficulties in communication and conflicts make social identities more salient. These types of negative group dynamics can hamper the work process and prevent teams from performing their optimal best. Lee and Schneider propose that team leaders who act as "identity crafter, emotion manager, psychological safety ensurer, and trust builder" can make a difference by helping teams maximize the benefits of harboring different identities by becoming truly global.

Chapter 8, entitled "Making a difference in the digital age: Global leadership and multiteam systems" is authored by Jeffrey Herman, Tracy McCausland and Daniel Bliton. There is a rise of multiteam systems defined as networks of interdependent teams. These systems have become a necessary way of organizing in the digital age, but they face complex challenges 
when combined with the cultural realities of today's connected world. Herman and colleagues suggest that research on such multiteam systems will expand our understanding of global leadership, especially as leadership happens in relational patterns of interaction among individuals. They posit that there is a need to overcome outdated assumptions about how we lead and how we learn, and an empirical illustration is provided. By simplifying assessment approaches global leadership learning outcomes can, the authors argue, offer a meaningful metric for how well global leadership makes a difference.

In Chapter 9 entitled "The new Millennial global leaders: What a difference a generation makes!", the authors Christina Butler, Ciara Sutton, Audra Mockaitis and Lena Zander take a close look at the "Millennial" generation. Generational cohorts may endorse different value systems and vary in their leadership expectations, and Millennials are found to, as a cohort, possess a distinct set of characteristics that differentiates them from earlier generations. After a description of three important global leadership roles: boundary spanning, blending and bridge making, Butler and colleagues examine how the Millennial generation, given their characteristics, can be expected to function in these roles. Some of the expected leadership roles and tasks may not come naturally and easy to them. On the other hand, Millennials bring new competences, such as being born digital natives, to their global leadership assignments. With the Millennial generation's strengths and weaknesses in mind, it becomes important for contemporary global leaders to make a difference by encouraging and supporting this future generation of global leaders in the right way so that they in turn can make a difference as global leaders.

Chapter 10 by Fiona Moore is entitled "Leadership for tomorrow: Taiwanese youth, ethnic identity and social networking". The chapter builds on findings from a London and Taiwan-based ethnographic study of recent graduates, young professionals and entrepreneurs. Moore finds that identity plays a critical role to the Taiwanese young diaspora as they engage in networking, boundary spanning and seeking out mentoring relationships to help them develop knowledge. Educational, ethnic, social and professional organizations become important in their careers, and for providing opportunities for leadership assignments in the future. As international social networks in this context are a prerequisite for global leadership, it is argued that these will contribute to the Taiwanese youth of today making a difference for tomorrow.

\section{Part II - Firms and Inter-Firm Partnerships: Making a Difference with Global Leadership}

The second part of the volume starts with Chapter 11 entitled "Responsible global leadership: A multi-level framework" by Günter Stahl, Christof Miska, Laura Noval and Verena Patock. They provide an overview of responsible global leadership (including ethical decision making, shared leadership and corporate social responsibility). Based on this, it is outlined how the context (organizational, institutional and cultural) of global corporations influences global leaders, and under which conditions these engage in responsible or irresponsible behavior. Stahl and colleagues illustrate with a real-life case how a global leader can make a difference by safeguarding ethical conduct and achieving triple-bottom-line outcomes (social, environmental and economic sustainability) both locally and globally. The "doing good" versus "avoiding harm" distinction underlines responsible leadership, and the authors remind us 
that, although responsible global leadership is highly complex and demanding, "it offers vast opportunities for global executives to make a difference for their companies and society".

Chapter 12 by Kate Daellenbach, Richard Seymour and Cynthia Webster entitled "Exploring responsible global leadership in corporate-community transactions" begins with historical real-life examples of corporate-community grand-scale involvement such as that of Cadbury's and Rowntree's establishments of villages with housing, public baths, playgrounds and sports fields for their employees in 1879. Daellenbach and colleagues define and examine corporate-community transactions, such as philanthropic gifts, philanthropic expenditure (donation or sponsorship), and philanthropic operational investment (shared value and social entrepreneurship), involving corporate entities and individual leaders. They remind the reader of one of their findings, namely that the motivation for such transactions needs to be carefully considered from both leader and community perspectives, and not only from the view of the recipients. The authors conclude that global leaders, with their ability to respond to complexity and diversity and to act responsibly and with compassion, have a possibility to make a difference to both firm and community by engaging in corporate-community transactions.

In Chapter 13 entitled "Beyond corporate social responsibility: Global leadership virtues that make a difference", Daina Mazutis and Christopher Zintel argue that for global firms to make a difference and "help solve the world's biggest problems such as climate change, poverty alleviation, human rights and resource scarcity" there is a need for a systems approach. They examine and compare traditional corporate social responsibility with a value chain approach, and a systems approach, and explain that business in the systems approach is a subset of our planetary ecosystem and cannot exist independently from social and environmental systems. For a systems approach to work, and have a positive impact, it needs global leaders of strong and virtuous character. Mazutis and Zintel identify six such virtues (wisdom, courage, temperance, transcendence, justice and humanity) and discuss how these can enable global leaders to make a difference by contributing to solving some of the planet's most critical social and environmental issues.

In Chapter 14, entitled "Inclusive leadership for the ethical management of cultural diversity", Laurence Romani and Charlotte Holgersson take a critical look at today's management of cultural differences and diversity management, which they claim is deeply unethical. Finding the business case for diversity management to be fundamentally flawed, and extant definitions of differences (such as grouping people into predetermined categories) highly questionable, they instead propose inclusive leadership as a way forward. Defining leadership as relational, instead of leader-centric, Romani and Holgersson draw on the cross-cultural management and diversity literature to outline a model for inclusive leadership based on three guiding principles: experience, understand and include. Global leaders who engage in inclusive leadership would in this way, the authors argue, move away from the ethical dilemmas of diversity management while engaging in responsible global leadership, which is a prerequisite for a sustainable society.

In Chapter 15 entitled "Developing global leaders who make a difference", Thomas Maak, Markéta Borecká and Nicola Pless have studied how global firms provide culturally challenging team-based learning experiences abroad through what is called "international service learning programs". Maak and colleagues outline a multistakeholder overview of the outcomes, benefits and best practices from three such programs on social engagement in developing countries: the Ulysses Program at PricewaterhouseCoopers, the Next Generation Development Program at HSBC and the Novartis Entrepreneurial Leadership Program. 
Although costly with long-term effects that are difficult to evaluate, it is clear that these programs make a real difference to the leaders, firms and communities where they take place. Global leaders gain experience, confidence, leadership skills and intercultural competence, as well as broader insight into sustainability issues and social problems, which enables global leaders to make a difference by acting responsibly.

Chapter 16 by Satu Teerikangas is entitled "Middle managers in mergers and acquisitions: Agents and recipients of change". Drawing on research on four Finnish industrial, globally operating firms' eight cross-border acquisitions, the challenge for middle management is what Teerikangas refers to as "double-hatting". That is to lead and manage such radical change initiatives as mergers and acquisitions, while simultaneously living through that very same change. The potential of middle managers to make a difference depends on their ability to combine these two roles, and to develop as a leader during the experience. If middle managers can learn to deal with their "inner world" of change, become more resilient, emotionally intelligent and develop a capability to manage radical change, they are more likely to develop into global leaders who can make a difference, as well as become better at enabling change in others.

In Chapter 17, entitled "Buffering and bridging: How leaders can make a difference during the post-merger integration process", the authors Güldem Karamustafa and Susan Schneider examine the actions taken by key individuals during the post-merger integration of a German family business by a large American publicly owned global firm. The integration of two global firms can generate a broad range of emotional and behavioral reactions among those concerned. Facilitating interaction and exchange becomes particularly important when two formerly independent organizations are to be merged to create value in concert. Global leaders who act responsively can alleviate tension, but also find ways of moving forward. Karamustafa and Schneider identify leadership actions intended to reduce intra-group and inter-group tensions ("buffering") and actions to provide a sense of stability and direction by ensuring continuity between the past and the present ("bridging"). Through buffering and inter-temporal bridging global leaders can make a difference during post-merger integrations.

Chapter 18 by Christina Wassenaar and Craig Pearce is entitled "The Nigerian leadership crisis: Is shared leadership the answer?". In a personal treatise of the topic, based on their own experience of working and living in Nigeria, Wassenaar and Pearce bring out the highlights and the depths of the leadership problem currently facing the country. As in global firms, the failure of leadership can take on many forms, but at its core there is a lack of social responsibility. In the case of Nigeria, it is the all-pervading corruption. Wassenaar and Pearce provide some hopeful examples of positive development and urge for increased transparency and checks and balances on power. Given that the latter are embedded in the philosophy of shared leadership theory, this approach could, they argue, provide a way forward towards increased transparency, responsibility and accountability, which is what is needed among leaders (and followers) in contexts like that of Nigeria to make a difference for the future.

\section{Part III - Universities and Business Schools: Educating Global Leaders to Make a Difference}

The third part of the book starts with Chapter 19 on "Taking the lead in making a difference: The role of business schools" by Stefan Gröschl, Patricia Gabaldón and Laurent Bibard. Business schools need to rethink their curricula, and how future leaders and members of society are educated. For too long business schools have promoted a bottom-line result-orientated 
agenda, where even sustainability has been addressed with profitability instead of responsibility arguments. Gröschl and colleagues propose that business schools can alternatively make a difference by developing interdisciplinary courses, which take a more holistic perspective at the subject areas taught, and by encouraging students to question and challenge what is taken for granted. Introducing a humanist perspective at business schools could lead to new ways of thinking and a focus on contribution to the common good. Faculty could encourage students to understand social, ethical and moral consequences of actions, and thus prepare and enable them to make a difference as responsible global leaders in the future.

Chapter 20 is entitled "Making a difference in the classroom: Developing global leadership competencies in business school students" by Mark Mendenhall, Lisa Burke-Smalley, Audur Arna Arnardottir, Gary Oddou and Joyce Osland. The question posed, and responded to, is whether global leadership competencies can be developed in business school students. Cognitive behavior therapy is proposed as a possible method. Students, according to this approach, can select a specific competency that they wish to improve, which is intended to motivate them to engage in their own development over the course of the term. They are also asked to prepare a detailed plan to focus on incremental progress, and find ways to buffer any negative thoughts that could occur during the process. Mendenhall and colleagues provide an empirical example, a case study of one student's attempt to develop a specific competency, illustrating the value of using cognitive behavior therapy in the classroom. The argument is that business schools can make a difference by helping students develop global leadership competencies. But also, in making the students realize that they have acquired a way to develop competences on their own, they can prepare and enable students to make a difference as future global leaders.

Chapter 21 by Joyce Osland and Gretchen Vogelgesang Lester is entitled "Developing socially responsible global leaders and making a difference: Global Leadership Lab social innovation projects". In this study, students are provided with the opportunity to work together on a social innovation project in a multicultural team, very similar to a "real" work experience. They have to create a social innovation submission for a university-sponsored competition. Working together in global teams can lead to developing a global mindset and gaining a better understanding of multiple perspectives, but also to learning about social problems, being creative and working towards a common good. Osland and Vogelgesang Lester conclude that despite being time-consuming and costly, social innovation projects can teach students the global leadership skills that they need in order to make a difference before and after they leave university.

Chapter 22 by Åsa-Karin Engstrand is entitled "Intersectional interventions in leadership education". Taking a critical perspective, and inviting students to take a critical intersectionality perspective, Engstrand reports on a course that she has developed on problematizing leadership. More specifically, the focus is on leader categorizations and cultural constructs, and the pedagogical approach draws on critical management education and norm-critical pedagogy. The focus of the course is to study how intersections of ethnicity, gender, age and other social identities operate in leadership constructions in the media. An example of how to design an intersectional leadership assignment, and student reactions to the same, is provided in the chapter. Engstrand does not shy away from addressing the pedagogical difficulties involved, e.g., questioning norms (more difficult regarding some norms than others), the potential impact of the teacher's own intersectionality and that dealing with multiple categories (and 
their intersections) is demanding for both student and teacher. The chapter is aimed to serve as inspiration for leadership teachers (and researchers) who want to make a difference.

Chapter 23 entitled "In search of responsible global leadership that makes a difference" by Allan Bird outlines an initiative by Northeastern University in the United States for academic scholars and corporate executives to meet and build a community. The Global Leadership Summit has successfully been organized over a number of years, and in this chapter the summit focusing on a theme of responsible global leadership is described in more detail. Drawing on different themes each year, keynote speakers are invited and panel discussions and thought leader sessions are organized with the theme in focus. In line with the overall goal of facilitating meetings across the academic-practitioner divide, the program encourages informal conversations during walks, over meals and at socializing coffee breaks. The Global Leadership Summit has explored issues in depth, led to a stimulating exchange of ideas, identified (new) difficult questions, and uncovered overlap and differences between practitioners and academics. Bird concludes that "an important prerequisite for making a difference is providing opportunities that inspire and enable people to make a difference".

Chapter 24 by Peter Zettinig, Udo Zander, Lena Zander and Audra Mockaitis is entitled "A world of learning: The future of management education based on academia and practitioner universitas". The authors argue that it is time to take seriously the idea of learning as a dynamic constructive process, which takes individual, situation-specific and contextual influences into account, and requires the learner to be an active provider of both questions and answers. Zettinig and colleagues propose that universities should become a contemporary version of what they originally were in Europe, universitas (communities) of masters and scholars leading a common life of learning and investigation together. In this proposed twenty-first-century vision, universitas would consist of practitioners who in interaction with faculty are encouraged to question established ways, seek answers, probe and to look for novel solutions to salient self-experienced and societal problems when pursuing executive education. This could pedagogically be realized through inquiry-based learning approaches and virtual learning platforms. A few promising examples from European contemporary university courses are provided. Reinvented universitas would enable universities to make a difference by engaging in a world of (continued) executive learning together with practitioners, which in turn will inspire and enable these current and future global leaders to make a difference.

Chapter 25 by Karsten Jonsen is the Epilogue titled "Developing holistic leaders - beyond the obvious". Observing that today's leaders are ill prepared to deal with social, environmental, ethical and other issues facing them, Jonsen focuses on what was a heart-felt topic for him, the education and development of holistic leaders. In the Epilogue he points to eight areas in dire need of research to move global leadership into the future: cultures are not always quantifiable, critical enlightenment, power-perspective studies, intersectionality, shared leadership, social identity conflicts, interventions, and mindful leadership. Jonsen draws on the chapters in this volume, carefully fitting their contributions into his own argument, when providing a broad-brush view of a research agenda for the study of global leadership. This Epilogue is a testimony to Jonsen's engagement in developing a more holistic understanding of leaders and global leadership. 


\section{SO, WHAT DO WE NOW KNOW ABOUT MAKING A DIFFERENCE WITH GLOBAL LEADERSHIP?}

Making a difference as a global leader presupposes many things, such as acquiring a plethora of competencies and skills, possessing certain individual characteristics and qualities as well as acting in an ethical and inclusive manner. It also becomes necessary to make sense of the relationships that you have with relevant others, to be culturally knowledgeable and aware, to be observant of your cultural surroundings, as well as being clued in as to what degrees of freedom you have in terms of leadership behavior in other cultural contexts. To this we can add that global leaders need to be attentive to how relevant others perceive social relationships and what they find motivating, but also how they make sense of interpersonal interactions, team processes and the like in order to understand their needs and expectations. Moreover, doing good rather than just avoid doing harm, and endorsing virtues such as wisdom, courage, temperance, transcendence, justice and humanity can support global leaders in their endeavor to act responsibly, while contributing to solving the critical social and environmental issues facing the world. This is all rather overwhelming, and probably much more than one individual can possibly grasp, let alone become and aspire for. On the other hand, global leaders need not, and cannot, necessarily be "fully trained and well accomplished" at the outset of their global assignment. Leadership grounded in inquisitiveness, and an interest in people and cultures are the first steps towards being able to act in a culturally aware, socially conscious and responsible way. If this genuine curiosity and learning about "the other" is coupled with a capacity to absorb and distill useful learning from one's own behavior and experience, global leaders will be able to improve and strengthen their interpersonal skills, as well as broaden and deepen their intercultural understanding over time.

Being a multicultural team leader and/or managing inter-firm partnership integration can become a transformational process with the capacity to hugely improve global leadership skills and competences. Leaders who work with radical change can find this to be a crystalizing experience as they live through the change themselves while providing support and guidance to others throughout the change process. Intense and demanding happenings, such as global mergers and acquisitions, provide opportunities to develop global leadership skill sets, such as buffering the team from external (and internal) tension, and providing a sense of stability and direction over time. With a better understanding of intra- and inter-group challenges, and the emotion that can come with these, leaders can engage in crafting team identity, providing psychological safety and building trust. Learning team leadership behaviors like these can prove most helpful when working with multicultural and global teams in other settings. Global leaders may moreover be active in other types of partnerships, such as corporate-community transactions, where their capacity to respond to complexity and diversity paired with responsibility and compassion can encourage and energize firms' willingness and ability to do good for society in progressive ways.

At the societal level, transparent and accountable, sometimes shared, global leadership is a promising recipe for countries as well as firms that have strayed away from the path that people want to take, and where culture, be it national or organizational, is far from ethical or inclusive. In such environments, cultural diversity is predominantly viewed as a source of conflict, people feel let down by the system and moving ahead is not based on meritocracy. This difficult situation is exacerbated by a lack of will or courage to take on the arduous tasks and challenging, yet necessary, socially conscious actions towards change. Yet, although the 
fact that shared, responsible and inclusive global leadership is indeed highly demanding, it has the potential to make a real difference to people, firms and societies in difficult corporate and societal environments.

When facing cultural multiplicity at work or in global teams, leaders will sooner or later engage in a set of roles and tasks. As globalization brings on challenges of particular concern to global team leaders, such as the need to interact across additional and different types of boundaries and address a larger diversity of stakeholders, team leaders need to engage in boundary-spanning activities. Another global leadership role is to overcome sub-grouping, polarization and faultlines in teams. The blending used to do this is similar to integrative leadership and builds on unifying processes. Global leaders also engage in bridge making between team members. The criticality of this role is witnessed by somewhat similar activities going under many names, for example cultural broker, cultural translator and cultural facilitator just to mention a few concepts that are the "same, same, but different". Metaphorically building bridges between team members to alleviate cultural misunderstandings and facilitate coordination also captures facets of integrative leadership, while practicing generative leadership is about drawing on multiculturalism as a resource to generate innovative solutions. To carry out these global leadership roles and tasks, leaders can draw on models that provide methods for engaging in intercultural interaction. These models start with mapping and experiencing culture, followed by taking a step back to decenter and understand, whereafter integration, or perhaps the contemporary more ethical practice of inclusion, can become feasible. Importantly, in this model diversity and multiculturalism are valued resources that can be experienced and understood to help make a difference with global leadership.

As a route towards developing culturally aware, responsible and socially conscious global leaders, internationally active firms offer their employees exciting opportunities. Examples include novel in-house training programs with actual real-life projects carried out in new cultural and social settings outside the firm; learning programs on leading and organizing in multiteam environments in the digital age; and exchange of knowledge and experience at inspiring meetings between practitioners and academics. In this way, global leaders can gain cultural awareness, practice and confidence as well as insights into sustainability, ethical and social issues. Developing global leaders who help to enact an organization's vision to make a difference and to instill positive change is, however, not solely the responsibility of global organizations and the people themselves, but also that of universities and business schools. Many future global leaders are educated within higher education systems where they are formed in terms of attitudes and beliefs about what constitutes contemporary best practices. We like to think of global leaders as possessing cultural "savoir-faire"1 and being culturally savvy, ${ }^{2}$ both indispensable to global leadership, but the question is what, apart from gaining experience from volunteering assignments and mindful traveling, could support students' global leadership development at universities and business schools?

Higher education courses offer great opportunities today. Knowledge and insights about learning processes and teaching effectiveness increase, develop and change, as do curricula and teaching methods. Good education has arguably become more learning-focused, creative and enquiry-based, ideally featuring all three rolled into one. Experience-based learning and "flipped classroom" are some contemporary examples. Novel approaches to the education of future global managers include drawing on cognitive behavior therapy when aiming to develop global leadership competences, providing experiential learning in global virtual teams tasked with social innovation and inviting students to scrutinize media using a critical intersectional 
perspective on leaders. These are direct and relatively immediate ways to inspire and empower students to make a difference in their future roles as global leaders. Taking a more long-term perspective on providing opportunities for students to develop into thoughtful, responsible and socially conscious global leaders comes with a call for a renewed role of business schools to adopt a more humanist and critical perspective. This would involve a continued broadening of university and business school education away from a singular focus on profit maximization, cost efficiency, competition and optimization. It could also mean a move towards modeling executive education as a collaborative learning adventure, where practitioners jointly with faculty identify critical questions, novel solutions and develop as global leaders in contemporary, revived universitas.

We can expect that increasing multiculturalism will alter and modify the shape of global leadership as we know it through those who will enact it over the years to come. For example, we can observe a growing number of biculturals and multiculturals in tandem with a larger movement of highly skilled migrants as well as refugees crossing borders to enter the workforce. For those of them who will work in the global arena, they will bring their experience and qualities to their assignments as global leaders. The incoming Millennial generational cohort may find certain aspects of global leadership challenging. However, they will also bring with them specific skills, such as those deriving from being a digital native by birth. Young members of the diaspora face other challenges than the local young, and try to cultivate contacts and networks in hope of acquiring their first leadership assignments. Even if early in tenure and young in experience, the support of mentors and social networks can help develop their confidence and competence. As the need for knowledgeable and culturally insightful global leaders increases, there is a parallel expectation that the young will develop global leadership skills and competences. This places high demands on universities, business schools and firms to provide a fertile ground for global leaders to grow their interpersonal and intercultural awareness, competences and skills. Noteworthy is the need to nurture and further develop future global leaders' learning ability and capacity, while recognizing them as complex intersectional individuals, instead of categorizing them into neat predetermined boxes. Such developments are fundamental to being able to encourage, engage and enable future global leaders to make a difference to people, firms and societies.

\section{CONCLUDING REFLECTIONS}

What makes this volume a unique read on global leadership is that it has brought together a large group of scholars who intelligently and passionately study, conceptualize, theorize and reflect on global leadership from the perspective of leaders and teams, firms and inter-firm partnerships as well as universities and business schools. Building on theoretical, conceptual and empirical work, the authors have examined contemporary issues by taking a fresh look at leaders and leadership in the global arena. Some chapters provide us with empirical evidence or illustrations, while others are based on theoretical reasoning. There are chapters critically questioning global leadership, while others are inspirational thought-pieces. Some chapters include contributions describing pedagogical methods, whereas others aim to broaden our minds about how universities and business schools can partner with practitioners in novel ways to educate global leaders for a future to come. Chapter themes and findings intersect in various ways to create a deeper understanding of the studied phenomenon. The chapters have 
in common that they are sincere and thought-provoking, while providing insightful input to theory and practice with implications for making a difference with global leadership.

I am also acutely aware of our responsibility as academics to contribute to making a difference by bringing our research forward, by sharing scholarly insights and by bridging the academic-practitioner divide. I hope that this volume on global leadership is seen not as a step but as a leap in the right direction. The overarching aim of this collection of chapters is to increase our knowledge and understanding of how leaders, teams and firms can and do make a difference with global leadership, and how universities and business schools can and do educate global leaders to make a difference. At the heart of global leadership lies engaging and interacting with people across differing cultural contexts, and with that comes great complexity and great responsibility. I believe that my fellow contributors to this volume would agree with me that if only one of the ideas presented in this book constitutes a seed that grows to make a difference, we would rejoice, although we of course hope to reach a broad readership with many of our ideas. Our aspiration has been to contribute to making a difference with our research, teaching, practice and - importantly to those around us - in our everyday life.

\section{ACKNOWLEDGMENTS}

To the 73 contributors in the Global Handbook of Leadership: Making a Difference, thank you - you made a difference! My gratitude also goes to the Swedish Research Council (Vetenskapsrådet) for the financial support of the Sigtuna workshop and for the time that I have been able to dedicate to this volume. And I would like to extend my thank you to Sigtuna Folkhögskola for the wonderful arrangements, service and hospitality. A note of thanks also to Professor Michael Morley at the University of Limerick for inviting me to co-chair a doctoral consortium. Apart from being such an enjoyable experience it was also the inception of this Research Handbook as this is where I met Francine O'Sullivan and attended Professor Nakiye Boyacigiller's keynote speech.

My grateful appreciation goes to Associate Professor Christina Butler, Professor Audra Mockaitis and Clinical Associate Professor Markus Vodosek for preparing the Academy of Management panel symposium submission together with me and for helping me to facilitate the three "sub-panels" - I could not have done this without you. Thank you also to all chapter authors who participated in the panels, and to the participants in the panel symposium session - your engagement was truly inspiring. I also wish to thank my colleagues at Uppsala University for the helpful feedback that I received at our internal research conference in June 2019. To the Department of Business Studies, and especially to Professor Ulf Holm and my colleagues in the International Business research group at Uppsala University, my appreciation for providing such an inspiring setting for research and writing. And to my colleagues globally - thank you for being there across time and space.

I would like to express my sincere gratitude to Professor Rick Steers for the Foreword, which in itself is a true contribution to this volume, and also take this opportunity to say thank you for your advice and support in my parallel role as Senior Editor at the Journal of World Business. It is with sadness that I express my gratitude to Karsten Jonsen for the Epilogue, such an important contribution to the book. Karsten passed away in 2018, but despite experiencing harsh side effects of his treatment, he was set on finalizing the Epilogue as well as his other work. I am grateful for this and also for the conversations we had about life. Thank you. 
My appreciation also goes to Annica Delfos, an acclaimed Swedish painter and installation artist living in Den Haag, the Netherlands, for giving us permission to use her striking painting W.S. 54 (painted in 2016, oilpaint on white paper $21 \mathrm{~cm} \mathrm{x} 29 \mathrm{~cm}$ ) from her installation "Watch and See" in Leiden, the Netherlands, 2017, on the book cover (for more information see https://annicadelfos.info/). This book would not look the same without it - thank you. Thank you also to Dana, Silva and Mira Zander for creating Figure 1.1 - it is a perfect map for the contents of the book. To my Mother, the rest of the family, the relatives, the in-laws and the friends - thank you for being you. And to my late Father (who by the way was always early) thank you. I miss you.

Thank you to Finn Halligan, Barbara Pretty and Dawn Preston for their always friendly, highly conscientious, and most helpful support in the last phases of this book project. Finally, my gratitude goes to the graciously patient Francine O'Sullivan, publisher at Edward Elgar, whose support throughout the process, especially when the going got tough, has been inspirational and indispensable.

\section{NOTES}

1. "Savoir-faire is the confidence and ability to do the appropriate thing in a social situation", accessed from www.collinsdictionary.com/dictionary/english/savoir-faire and "Capacity for appropriate action", accessed from www.merriam-webster.com/dictionary/savoir\%20faire on July 20, 2019.

2. "Savvy" as in "having or showing perception, comprehension ... especially in practical matters", accessed from www.merriam-webster.com/dictionary/savvy and possessing "practical knowledge and ability", accessed from https://dictionary.cambridge.org/dictionary/english/savvy on July 20, 2019. 